\title{
Símbolo, racionalidad y filosofía en Mauricio Beuchot y Andrés Ortiz-Osés ${ }^{1}$
}

\author{
Patricia Vargas García \\ UNIVERSIDAD IBEROAMERICANA. MÉXICO
}

\section{Resumen:}

En el proceso para revalorar al símbolo como camino a la verdad, que emerge sobre una trayectoria ascendente desde Nietzsche, Cassirer, Nicol, Gadamer hasta Ricoeur, aquí se convocan las aportaciones de la Hermenéutica Analógico Icónica de Mauricio Beuchot y la Hermenéutica Simbólica de Andrés Ortiz-Osés. Se contrastan sus reflexiones enfocadas a la revisión de la naturaleza del símbolo, si posee una racionalidad que contribuya con las pretensiones filosóficas de universalidad.

Palabras Clave: Símbolo, racionalidad, hermenéutica, Mauricio Beuchot, Andrés Ortiz-Osés.

\section{Abstract:}

In the process to reexamine the symbol as a way to the truth, which springs up over an ascendant trajectory from Nietzsche, Cassirer, Nicol, Gadamer to Ricoeur, here the Mauricio Beuchot's contributions in Analogic Iconic Hermeneutics and the Symbolic Hermeneutics of Andrés Ortiz-Osés are called forth. Their approaches about the nature of the symbol are contrasted looking for a rationality that contributes with the philosophic aspiration of universality.

Keywords: Symbol, rationality, hermeneutics, Mauricio Beuchot, Andrés Ortiz-Osés.

1 El presente trabajo fue extraído de "Analogicidad y simbolismo: una comparación crítica entre dos modelos hermenéuticos", tesis con la que se obtuvo el grado de Maestría en Filosofía con mención honorífica en la UNAM, en 2011 . 
La racionalidad del símbolo es punto central en la discusión sobre su naturaleza, pues de ello depende su integración como objeto de la Filosofía Hermenéutica. Por un lado, la búsqueda de la verdad se potencializa en el terreno movedizo de lo simbólico, al tiempo que crece el riesgo de hacer de la filosofía un albergue de imaginerías, simples conjeturas, o meras invenciones. Los hermeneutas que aquí convocamos han querido correr el riesgo, no sin precaución, cada quien según su perspectiva, para no perderse o caer en el abismo de los significados. Mauricio Beuchot y Andrés Ortiz-Osés han reconocido, cada uno a su modo, la tensión generada por la búsqueda de un conocimiento universal capaz de respetar la multiplicidad de lo particular y se han enfrentado a la disyuntiva entre la profundidad y el progreso, y persisten en querer descifrar la verdad filosófica a través del símbolo cuidando de respetar su significación viviente. Así lo quiso ya Paul Ricoeur, al sentar un valioso antecedente de cómo adentrarse filosóficamente en el mundo del simbolismo.

Como introducción al tema mencionaré algunos rasgos de la historia de la filosofía hermenéutica que vincularon irremisiblemente la interpretación por el camino del símbolo. Enseguida, presentaré en forma de contraste algunos puntos angulares de las teorías sobre el símbolo, de la Hermenéutica Simbólica y la Hermenéutica Analógico-Icónica, con miras a comprender cómo estas hermenéuticas desarrollan filosofía a partir de sus estudios sobre el símbolo, y cuáles son los matices que las diferencian entre sí. El contraste entre estos dos modelos hermenéuticos aportará al lector mejor comprensión de la naturaleza del símbolo y su vínculo con la filosofía. Dejaré para mejor ocasión la controversia entre estos dos modelos hermenéuticos sobre la dimensión sígnica del símbolo.

Durante la historia de la ciencia y la cultura del siglo xx, el símbolo ha sido revalorado. Uno de los detonadores de esta vuelta al símbolo se encuentra en Gadamer y su influyente afirmación:

[...] es una tarea propiamente filosófica —al menos para la tradición europea de la filosofía que vive mirando de reojo a la ciencia- hacer justicia a la dimensión de lo mítico [...]. La tendencia objetivadora de la conciencia (y no sólo la de la moderna ciencia) debe ser compensada con la experiencia mítica. ${ }^{2}$

2 Hans Georg Gadamer. Mito y razón. Barcelona: Paidós, 1997, p. 64. 
En esta revaloración se concentran las miradas que atendieron con anterioridad al símbolo desde diversas perspectivas hermenéuticas. Nos referimos al caso de Nietzsche, todavía en el romanticismo del siglo XIX, y de Cassirer, ya en el siglo XX.

Nietzsche desconfió del concepto y del principio de identidad, y así lo manifestó:

La lógica está vinculada a una condición: dar por sentado que haya casos idénticos. De hecho, para que se piense y se concluya lógicamente, primero es necesario fingir cumplida esa condición. Esto significa que la voluntad de verdad lógica sólo puede llegar a cumplirse tras haber aceptado un falseamiento por principios de todo acontecer... ${ }^{3}$

En otras palabras, detrás del principio de identidad no hay una voluntad de verdad, sino de poder. Su desconfianza hacia lo conceptual y sus principios indica como alternativa para continuar un rumbo como el del símbolo. Por otro lado, el valor epistemológico del símbolo fue descubierto por Ernst Cassirer quien observó que el hombre no sólo crea símbolos para interpretar el mundo, sino que en sí mismo es un "animal simbólico". Sus estudios revelaron que el mundo humano lo configuramos a partir de modalidades simbólicas: la forma mítica (religión y arte), la forma lógica (matemáticas y ciencias naturales) y la forma lingüística (lenguaje natural, filosofía y ciencias de la cultura). Esta revaloración del símbolo nos instiga a revisar la vieja pretensión científica de objetividad, pues ahora hay que integrar la subjetividad:

El hombre no puede enfrentarse ya con la realidad de un modo inmediato [...] La realidad física parece retroceder en la misma proporción que avanza su actividad simbólica. En lugar de tratar con las cosas mismas, en cierto sentido, conversa constantemente consigo mismo. ${ }^{4}$

3 Nietzsche apud Albrecht Wellmer. Sobre la dialéctica de modernidad y postmodernidad. La crítica de la razón después de Adorno. España: Editorial Visor, 1993, p. 145.

4 Ernst Cassirer. Antropología filosófica. México: FCE, 2006, pp. 47-48. 
La razón hermenéutica toma significado como la razón humana, plural, entendida en un sentido extendido, capaz de integrar dialécticamente la razón formal con su opuesto perteneciente a la región de la imaginación simbólica (como la llama Gilbert Durand), nombrada por otros razón poética o razón estética. Pero si queremos que esta integración sea armónica tendremos que pensar en la noción de Heráclito, cuando decía que "armonía es contrariedad, como en el caso del arco y la lira."5

El reto de configurar un método adecuado a la naturaleza del símbolo lo asume Paul Ricoeur, y para ello en su obra El conflicto de las interpretaciones aplica esquemas interdisciplinarios del estructuralismo, el psicoanálisis y la dialéctica hegeliana, con lo que completa su modelo metafórico. Indagar sobre el símbolo es pensar a partir de él. Así, con claridad, explica:

No se trata en absoluto de ceder a no sé qué intuición imaginativa, sino de elaborar conceptos que comprendan y hagan comprender conceptos coordinados según un orden sistemático, en un sistema cerrado. Pero al mismo tiempo, se trata de transmitir, por medio de esta elaboración racional, una riqueza de significado que ya estaba allí, que desde siempre ha precedido a la acción racional. Pues esta es la situación: por una parte, todo ha sido dicho antes de la filosofía, por el signo y el enigma [...] Por otra parte, nuestra tarea es hablar claramente. ${ }^{6}$

La revaloración del símbolo y lo simbólico realizada a partir de la obra de Ernst Cassirer por un lado, y también de las investigaciones de Mircea Eliade, por otro, han impactado la hermenéutica vigente. Por eso ahora el símbolo es tema central en la reflexión hermenéutica, especialmente conectado con sus orígenes mítico-religiosos o con el doble sentido del lenguaje.

En este proceso de revaloración del símbolo se suman también las aportaciones de Eduardo Nicol. Él revalora al símbolo porque le interesa el ser humano y dice que el hombre es el ser que expresa, pero además agrega que "expresa simbólicamente". No señala con

5 Heráclito. Fragmento 51.

6 Paul Ricoeur. El conflicto de las interpretaciones. Ensayos de hermenéutica, Argentina. Fondo de Cultura Económica, 2003, p. 269. 
ello características accidentales o contingentes, sino que apunta a la naturaleza humana misma: "la forma de ser humana ha de conceptuarse entonces, ontológicamente, como simbólica”. ${ }^{7}$ De aquí que se ocupara de estudiar las relaciones del símbolo y las haya expresado como cinco principios. ${ }^{8}$

Mauricio Beuchot especifica tanto su interés por el símbolo como la natural asociación de éste con la analogicidad con un nuevo término que, como Raúl Alcalá comenta ${ }^{9}$, se agrega a la Hermenéutica Analógica como un apellido: Icónica. Por su cuenta, la filosofía de Ortiz-Osés también expresa este "giro simbólico" de la nueva hermenéutica y desde su inicio toma el nombre de Hermenéutica Simbólica. Independientemente de los nombres con los que se las identifica, ambas hermenéuticas, al igual que la de Paul Ricoeur, son simbólicas. Pero ¿lo son en el mismo sentido? ¿Cuáles son las diferencias entre ambas hermenéuticas, en concreto con respecto al símbolo?

\section{a) La relación entre racionalidad y símbolo}

La conexión entre imaginación y símbolo siempre se encuentra presente, como condición necesaria, en todas las formas simbólicas, por lo que es la parte destacada de su naturaleza, como Gilbert Durand enfatiza en su libro La imaginación simbólica. Un problema generado de la vinculación entre imaginación y símbolo es que este último entonces puede dificultar su relación con la verdad, en especial con la noción de verdad como correspondencia, por lo que un camino para salvar este enredo tendría que hallar cierta racionalidad en el símbolo.

7 Eduardo Nicol. Metafísica de la expresión. México: FCE, 1957, p. 350.

8 Los cinco principios consisten, a saber, en que el símbolo es un producto del hombre, que cumple una función dialógica, con un contenido significativo, que a su vez pertenece a un sistema de símbolos, y que es inseparable de su relación con el pasado histórico. Cfr. Ibidem, capítulo undécimo.

9 Raúl Alcalá Campos. Hermenéutica, Analogía y Significado. Discusiones con Mauricio Beuchot, México: Fes Acatlán UNAM, 2004, p. 129. "En el apéndice de la segunda edición de su Tratado de hermenéutica analógica, Beuchot le pone apellido a su analogía, convirtiéndola en una hermenéutica analógico-icónica, que se centra en el símbolo, es decir, es una hermenéutica simbólica, o como él mismo dice, simbolista, simbolizante". 
En esta red problemática se mantiene, por un lado, la controversia sobre la ruptura que puede haber entre lo racional y la imaginación, y por otro lado, como atizando el fuego, se encuentra el elemento inconsciente del símbolo, que también podría restarle potencia a su racionalidad. De alguna manera, si racionalidad e imaginación se distinguen pero no se contraponen, de todas formas persistiría la necesidad de explicar cómo es que ellas pueden converger armónica o conflictivamente en la naturaleza del símbolo. $\mathrm{Y}$ en lo que se refiere al inconsciente, podría reducirse el símbolo a mera expresión pulsional, lo cual de manera obvia desalentaría la atención de la filosofía hacia el símbolo. En el trabajo para enfrentar estos problemas con respecto al símbolo, revisamos aquí las teorías del simbolismo de nuestras dos ramas hermenéuticas.

La racionalidad del símbolo es defendida por la Hermenéutica Analógico-Icónica, mientras que la Hermenéutica Simbólica la rechaza y, no obstante, subraya la importancia del símbolo para la filosofía. El reto de la Hermenéutica Analógico-Icónica al defender la racionalidad radica en que esto podría lastimar la vitalidad del simbolismo hasta destruirla, mientras que el reto de la Hermenéutica Simbólica consistiría en justificar al simbolismo como objeto de la Filosofía, aun al acentuar su parte inconsciente, imaginativa y caótica. En los siguientes apartados revisaremos cómo las hermenéuticas que nos ocupan comprenden la racionalidad, conjugada con los diversos atributos del símbolo.

\section{b) Lo que el símbolo une}

Para empezar a revisar el tema podemos hacer referencia a la explicación que del símbolo hace Nicol y que comparten los teóricos del símbolo en general:

Se llama símbolo en Grecia, [...] a cada una de las dos mitades de un objeto que se divide y que, al reunirse permiten identificar a los portadores, como si fueran unas credenciales. Pero estas credenciales, el hombre no las lleva consigo para exhibirlas, sino que su ser mismo consiste ya en una tal prueba de identidad. ${ }^{10}$

10 Eduardo Nicol, op. cit., p. 350. 
Para esta genealogía; Mardones abona el señalamiento de la etimología de sym-bolon y dice que "la palabra procede del verbo griego ballein (lanzar) que, junto con el prefijo sym, quiere indicar un movimiento de reunificación de las partes separadas". ${ }^{11}$ Mauricio Beuchot enriquece la etimología al afinar el significado como "arrojar o yacer conjuntamente dos cosas que embonan entre sí y, por lo mismo, que son partes de una más completa, como una moneda, una medalla"12, pero sobre todo precisa que curiosamente "la palabra 'símbolo' tiene la misma etimología que 'conjetura'”. ${ }^{13}$

Mauricio Beuchot dice que el símbolo tiene una parte empírica y particular, que conocemos primero, y que a partir de ella iremos en busca de la parte desconocida, que es conceptual. Pero lo que más caracteriza al símbolo es que une dos elementos, dos dimensiones, es factor de comunidad, como lo material con lo espiritual, lo empírico con lo conceptual, lo literal con lo metafórico, lo onírico con lo vigilante, lo empírico y lo trascendental, lo particular con lo universal. ${ }^{14}$

Por su cuenta, Andrés Ortiz-Osés además de coincidir con lo anterior lo refuerza, al otorgarle una importancia central en su teoría del símbolo, cuando dice que en él los opuestos conviven implicados y por ello, la naturaleza del símbolo a su vez representa el presupuesto de implicacionismo ontohermenéutico y dice: "es nuestra hipótesis cum fundamento in re: con fundamento en la experiencia humana del mundo referida a la conspiración de todo en el complot o coimplicación del ser". ${ }^{15}$

11 José María Mardones. "La racionalidad simbólica" en Blanca Solares y María del Carmen Valverde Valdés (ed.). Sym-bolon. Ensayos sobre cultura, religión y arte. México: Instituto de Investigaciones Filológicas, Centro Regional de Investigaciones Multidisciplinarias, UNAM, 2005, p. 64.

12 Mauricio Beuchot. "Hermenéutica, analogía, ícono y símbolo" en Blanca Solares y María del Carmen Valverde, op. cit., p. 76.

13 Mauricio Beuchot. Hermenéutica analógica, simbolo, mito y filosofia. México: UnAm, 2007, p. 14. Aquí señala que es Nicolás de Cusa quien apuntó esta coincidencia, ya que conjetura viene de la composición entre CUM=con y IACTARE=echar o lanzar.

14 Mauricio Beuchot. "Hermenéutica, analogía, ícono y símbolo" en Blanca Solares y María del Carmen Valverde, op. cit., p. 76.

15 Andrés Ortiz-O. Amor y sentido. Barcelona: Editorial Anthropos, 2003, p. 175. 
¿Existe acaso alguna diferencia de fondo al reconocer en el símbolo ya sea un factor de comunidad o ya la implicación de los opuestos? Ambas hermenéuticas, la Analógico-Icónica y la Simbólica, están de acuerdo en que el símbolo reúne, junta. Quizá la diferencia pueda consistir en que al hablar de opuestos implicados se subraya el carácter necesario de la oposición. La sutileza está en que para Ortiz-Osés lo que el símbolo reúne son siempre opuestos y muchas veces contradictorios. Aquel principio del implicacionismo ontohermenéutico de la Hermenéutica Simbólica asume los contrarios de forma remediadora, y presenta al hombre simbolizador que implica los opuestos compuestos como un Homo implicator. ${ }^{16}$ Al simbolizar, el sujeto envuelve los opuestos y en simultaneidad su disolución o fusión es impedida para que la polaridad persista. Mientras que para Beuchot, el símbolo congrega lo plural, lo distanciado, pero a su vez semejante, y aquí lo dice: "El ícono es precisamente un tipo de signo que se basa en alguna semejanza con lo significado". ${ }^{17}$ Y la semejanza se basa en alguna propiedad como cualidad, relación o asociación de conceptos o de significaciones. También, como el símbolo junta lo semejante, es que se expresa a través de la poética recuperación de las palabras de Nicolás de Cusa:

Sin embargo,

Nicolás de Cusa dijo algo

aún más estremecedor:

"Os doy este ícono, hermanos,

para que no olvidéis que icono de

Dios,

es cada cosa, por pequeña y

por insignificante que sea, pues significa todo en ella".

16 Ibidem, p. 115. También cfr.: Andrés Ortiz-Osés. Visiones del mundo. Bilbao: Universidad de Deusto, 1995, p. 213: “im-plicare dice transitivamente 'envolver' e intransitivamente 'impedir'”.

17 Mauricio Beuchot. Las caras del símbolo: el ícono y el idolo. Madrid: Ed. Caparrós, 1999, p. 22. También en Mauricio Beuchot. Hermenéutica analógica, símbolo, mito y filosofía, México: UNAM, 2007. "Lo típico, entonces, del símbolo, es que sirve para reconocer al otro, al semejante, al análogo.” p. 46. Más adelante también observa: "Es el que nos lleva de la parte a la totalidad, y de los efectos a las causas". p. 52. 
$Y$ es que cada cosa

es un trozo,

un fragmento,

arrancado de la totalidad, y encierra

el todo en su potencia,

como en semilla. ${ }^{18}$

Por un lado, Mauricio Beuchot atiende que el símbolo sirve para reunir semejantes, ya sean significados o personas con alguna semejanza, pero los significados que une el símbolo parece que guardan la relación entre ellos del todo con la parte, y del efecto con la causa, por su función metonímica. Esos significados en efecto pueden ser distantes y opuestos, sin embargo, entre ellos guardan esa relación de analogía, si hay bien y mal llega a triunfar el bien. En cambio, para Ortiz-Osés lo que une el símbolo re-mediadoramente, tanto por su uso entre personas como entre sus significados, son opuestos (contradictorios) como el bien y el mal, el ser y el no-ser, lo bello y lo feo. El símbolo no los resuelve, ni mucho menos los disuelve, persiste la oposición en trágica tensión, lo que nombra sintaxis coimplicativa, no síntesis, pues los contrarios no guardan una relación dialéctica, sino dualéctica (sic).

\section{c) La conexión con el universal y el desarrollo de la ontología}

La capacidad universalizadora es el rasgo que Mauricio Beuchot más destaca de la naturaleza del símbolo. Aunque reconoce al ser híbrido del símbolo, donde hay una parte irracional e inconsciente, subraya la parte racional y consciente. Por eso dice que esa capacidad universalizadora se observa por ejemplo en la conexión del símbolo con la vida humana en comunidad, donde su función es vincular afectivamente, y así los símbolos constituyen las culturas y las conectan entre sí. ${ }^{19}$ De acuerdo con esto, entonces, nos parece que aquí la parte racional del símbolo se manifiesta por ser factor de

18 Mauricio Beuchot. Poemas de desierto. Coahuila: Instituto Coahuilense de Cultura, 2003, pp. 207-208.

19 Mauricio Beuchot. "Hermenéutica, analogía, icono y símbolo" en Blanca Solares y María del Carmen Valverde, op. cit., 2005, p. 86. 
comunidad, por tener poder unitivo. Y, sin embargo, precisamente de esta condición del símbolo, según la versión de Ortiz-Osés, que reúne implicando, es que el símbolo se distingue de la razón. Y lo explica al referir el símbolo al lenguaje, por considerar a este último en esencia simbólico. Él dice que "la razón desimplica, explica o libera la esencia eidética por abstracción, [mientras que] el lenguaje es la explicación implicativa de lo real”. ${ }^{20} \mathrm{El}$ synbolon es reunión de ser y no-ser.

La disociación sostenida entre símbolo y razón no es obstáculo para que Osés también sostenga que el simbolismo conecta con lo universal. Pero, ¡si no es de una parte racional del símbolo, entonces cómo puede Ortiz-Osés encontrar esta conexión con lo universal? Para ello recurre a Heidegger como trasfondo de su desarrollo, no al primero, sino al segundo, el del Ser que es Presencia que nos presencia; y al tercero, el que dice que el Ser acontece en el lenguaje. Él señaló la dimensión ontológica del lenguaje, o sea, simbólica, pues hay una reunión de contrarios. De la misma manera que en el lenguaje ontológico heideggeriano subyace el logos de Heráclito, como articulación de opuestos en reunión radical. ${ }^{21}$ Pero ahora hace falta ver cómo ese logos heracliteano que señala Heidegger hace posible la universalidad del símbolo y, sin embargo, se distingue de la razón.

La respuesta de Ortiz-Osés dice así:

El logos parmenídeo se funda en el logos heraclíteo. El logos heraclíteo no dice razón, sino fundamento, "reunión" producida no por el pensar humano, sino por la fuerza imperante, predeterminante y totalizante de la Physis emergente: el Ser como natura naturans. ${ }^{22}$

En otras palabras, cuando Ortiz-Osés distingue al símbolo de la razón lo está distinguiendo de la abstracción que separa esencias, pues el símbolo en vez de separar, reúne. Y a esta condición implicadora del símbolo subyace el logos como juntura fundamental de

${ }^{20}$ Andrés Ortiz-Osés. Metafísica del sentido. Una filosofía de la implicación. Bilbao: Universidad de Deusto, 1989, p. 33.

21 Andrés Ortiz-Osés, op.cit., p. 32.

22 Andrés Ortiz-Osés. La nueva filosofía hermenéutica. Hacia una razón axiológica posmoderna. Barcelona: Editorial Anthropos, 1986, p. 82. 
todo lo existente. La condición implicadora del símbolo es consecuencia entonces del juego natural de opuestos de todo lo existente, y por eso sostiene que el símbolo da paso a lo universal. El símbolo encuentra su fundamento fuera del pensamiento humano en el Ser. Nosotros entendemos que el silogismo subyacente diría que, si el lenguaje es nuestra vía de acceso al ser y el lenguaje es una forma simbólica, entonces el símbolo es nuestra liga con el ser.

Por su cuenta, el planteamiento de la Hermenéutica Analógico-Icónica se interesa en el símbolo porque mira en él un vigoroso camino para el futuro de la ontología. Beuchot nos recuerda valiosos y representativos ejemplos de filósofos que por medio del símbolo, y en específico en la poesía y su contenido simbólico, han buscado el desarrollo ontológico, y que seguramente le han inspirado. ${ }^{23}$ Entre esos ejemplos señala las líneas germinales que Ricoeur nos brinda para elaborar una ontología a partir del símbolo, y atrás de él Gadamer y el propio Heidegger, para quien el ser canta en la poesía; y también Juan David García Bacca, en especial en sus glosas de Antonio Machado; María Zambrano, quien recoge de Unamuno y Ortega la idea de una razón poética; y también Ramón Xirau quien piensa que el ser se nos muestra como presencia ausente en la poesía.

\section{d) Símbolo e inconsciente}

Es posible que debido a la intención de subrayar la racionalidad del símbolo, los estudios de Mauricio Beuchot muchas veces marginen la parte inconsciente del símbolo. Son escasos los señalamientos al respecto, y al hablar del símbolo da a entender la parte inconsciente, al mencionarla sólo de pasada, por ejemplo cuando dice que "el símbolo nos hace pasar lo inconsciente a la conciencia”. ${ }^{24}$

23 Cfr. Mauricio Beuchot. Hermenéutica analógica, simbolo, mito y filosofía. México: UnAm, 2007, p. 100, donde afirma "que la metafísica se hace no tanto en la poesía, sino desde la poesía. Como una recuperación reflexiva y abstracta del contenido concreto y directo o inmediato de la poesía y de otros símbolos".

24 Mauricio Beuchot. "Hermenéutica, analogía, icono y símbolo" en Blanca Solares y María del Carmen Valverde Valdés, op. cit., p. 86. Y antes apenas 
Hay espacios donde nos hubiera gustado que detallara explicaciones, como por ejemplo si hay o no conexión entre el inconsciente colectivo de Carl Jung y los sedimentos de sabiduría que hay en los mitos. ${ }^{25}$ En sus Perfiles esenciales se contenta con reconocer el poderoso componente psicológico del símbolo, y con expresar que le parece difícil aceptar la teoría de los arquetipos universales de Jung, y sin embargo, menciona esa teoría para fortalecer la conexión entre símbolo e imagen, o mejor, las imágenes simbólicas. ${ }^{26}$

En contraste, Ortiz-Osés subraya con insistencia la parte inconsciente del símbolo, además se adherirse de manera reflexiva a la teoría de los arquetipos de Jung, y que de hecho se integró al llamado Círculo Eranos. ${ }^{27}$ Lo que Osés recoge de Jung es la teoría que sostiene que el lenguaje simbólico funciona como liga entre lo consciente y lo inconsciente como estructura de doble vía, de ida y vuelta. Lo simbólico para Jung también es efectivo para llevar a la conciencia los nudos de asociaciones inconscientes llamados complejos y así lograr su integración. Lo inconsciente y arquetípico, lo complejo, logra conectarse con lo típico consciente, para liberarse, y el medio por el cual se logra esto es el simbolismo, que lleva a cabo una realización cultural del sentido. ${ }^{28}$ Desde la perspectiva

señaló: "Nos hace pasar, a veces sin darnos cuenta incluso, para colocarnos, cuando menos lo pensamos, del otro lado del límite ('al otro lado del espejo', como diría Lewis Carroll, y fue lo que él siempre anduvo buscando)”, p. 79.

25 Mauricio Beuchot. Hermenéutica analógica, símbolo, mito y filosofía. México: UnAm, 2007, p. 59. Aquí nos recuerda que para Aristóteles el filósofo era amante de los mitos precisamente por ese 'sedimento' de sabiduría. 26 Después de la presentación de esta tesis de maestría, Beuchot publicó El poder del ícono: Jung el alquimista de la psique. México: Ed. Planeta, 2015. Aquí distingue que Freud iba a los signos, mientras que Jung iba a los símbolos. También revisa esa misteriosa relación entre psicología y alquimia, con base en los estudios de Jung para demostrar que los procedimientos de la alquimia transformaban la psique del sujeto practicante. Valora cómo Jung ayuda a vivir.

27 Para una explicación de los orígenes del Círculo Eranos, sus propósitos y sus integrantes, ver Andrés Ortíz-Osés, 1995, pp. 23-43.

28 Ibidem, p. 49. Los arquetipos están "en el fondo de la psique simbolizando las configuraciones del sentido y la complejidad de lo simple, así como lo implicado o no-dicho en lo dicho y explicado". 
de Jung, los arquetipos son estructuras energéticas del inconsciente colectivo que predisponen la psique. Esta idea fue enriquecida luego por H. Corbin en el mismo Círculo Eranos, con la variedad de que describe los arquetipos como prototipos eidéticos (no tanto energéticos), lo cual acentúa su precipitación en imágenes. Entonces, en lugar de hablar del inconsciente colectivo, Corbin habla del imaginal. Pero Ortiz-Osés piensa que este giro corre el riesgo de convertir lo arquetípico profundo en puro tipo superficial, como la evanescencia posmoderna, y dice: "[He] optado por presentar lo simbólico como estructura mediadora entre lo arquetípico y lo típico, así pues entre el arquetipo y su imagen, en cuyo caso [se puede] hablar con rigor de un Imaginario simbólico". ${ }^{29}$

La Hermenéutica Analógico-Icónica, respecto al símbolo como lenguaje del inconsciente, ofrece un tratamiento marginal, sus afirmaciones lo presuponen, pero sin mayores explicaciones por lo menos en el Tratado o Los perfiles, y tampoco comenta gran cosa en los textos avocados al símbolo, como Hermenéutica, analogía y símbolo o en la muy especializada obra Hermenéutica analógica, símbolo, mito y filosofía. Para detallar sobre algunas aplicaciones de la hermenéutica al lenguaje inconsciente, es preciso buscar entre otros textos periféricos de la Hermenéutica Analógico-Icónica, como el estudio Hermenéutica, lenguaje e inconsciente, por el que podemos conocer parte de sus conexiones con la filosofía de Paul Ricoeur, y también ofrece una muy interesante fundamentación teórico filosófica a la técnica dirigida a los significados vivenciados, de Eugene T. Gendlin llamada "focalización".

Esta focalización de Gendlin, como nos la expone Mauricio Beuchot, observa que el pensamiento es mediador entre la realidad externa y la expresión lingüística con la que interactúan las pulsiones inconscientes y así se logran patrones de respuesta ante estímulos. Ésta es una hermenéutica auto-implicativa porque interpreta tanto el que escucha como el que habla. La focalización recupera la vivencia humana sin por ello dejar perder la lógica, por eso se vuelve punto intermedio entre filosofía analítica y existencialismo. La focalización parte del hecho que Beuchot llama "inefabilidad no tan inefable", refiriéndose a la humana dificultad para expresar significados vivenciados, por pertenecer éstos al ámbito pre-conceptual,

$29 \quad$ Ibidem, p. 27. 
y por eso la metáfora se convierte en una forma expresiva natural para ello. Lo imaginativo, simbólico es lo que suscita el tránsito de lo pre-conceptual a la expresión. ${ }^{30}$

Pensamos que es importante resaltar la hipótesis que defiende Beuchot de que los significados vivenciados están cargados de afecto y emociones, son pre-conceptuales, con estructura pre-verbal, y que no obstante su proximidad con la expresión imaginativa no son meramente irracionales, luego, tampoco pulsionales, y tienden intencionalmente a la conceptualización. Pero lo que se puede conceptualizar es su expresión, pues ellos permanecen de manera pre-conceptual, por lo que este proceso no es desimbolizante. La relación implicante entre afecto y concepto la conseguimos con la reflexión. Por ello concluye Mauricio Beuchot al afirmar con Ricoeur que "el significado vivenciado es un símbolo, se expresa simbólicamente". ${ }^{31}$ Gracias a estas características, se colige con facilidad que desde la Hermenéutica Analógico-Icónica el símbolo también puede ser camino hacia el concepto.

30 Cfr. "La pugna de Mauricio Beuchot por la Hermenéutica” en Raúl Alcalá Campos, op. cit.: "Beuchot por otro lado, aplica el modelo tomista del conocimiento y la formación de significados a los 'significados vivenciados'. Este modelo consiste en el paso de la experiencia por cuatro energías o facultades: 1) el sentido común, 2) la imaginación o la fantasía, 3) la vis cogitativa y 4) la memoria sensitiva. La primera unifica y estructura las impresiones de los sentidos externos, la segunda permite llegar a la abstracción (al no requerir la presencia del objeto), otorgando una mayor carga de significación, la tercera, es la que aprehende esta significación (la cogitativa es precisamente la que forma los 'significados vivenciados'); la cuarta, unida con la tercera, permite la ulterior elaboración del intelecto". pp. 19 y 20. De la reseña crítica de Raúl Alcalá extraemos esta síntesis: "El modo de expresión que sostiene Beuchot presenta tres aspectos dinámicos: experiencia (externa e interna), pensamiento y lenguaje, de tal manera que las cosas de la experiencia son significadas primero por el pensamiento (pre-conceptual y conceptual) y después por el lenguaje”. Ibidem, pp. 22-21. Más adelante precisa: "Esto recoge la parte sincrónica de la estructura. Dentro del aspecto diacrónico (proceso genérico), encuentra que a) el hombre es afectado por el objeto (experiencia externa), pero también, entre otras cosas, por las pulsiones inconscientes (experiencia interna); b) a partir de lo anterior se forma una palabra interior; y $c$ ) expresa esta última como palabra exterior que ha formado en sí mismo". Cfr. Ibidem, p. 168.

31 Mauricio Beuchot. Hermenéutica, lenguaje e inconsciente. México: Universidad Autónoma de Puebla, 1989 p. 177. 
Cuando lo inconsciente es conectado a la conciencia mediante el símbolo, algo sucede en el interior de la persona. Dice Beuchot que "el hombre [...] deja salir algo que lo bloqueaba en su proceso y se siente aliviado". ${ }^{32}$ "El símbolo da paz, quita la tensión, deja ir la angustia". ${ }^{33}$ Luego de este análisis, vemos que no termina por aceptar que los significados vivenciados pertenezcan al ámbito inconsciente, y mucho menos que sean irracionales, sólo son de estructura pre-verbal. Hasta aquí también podemos observar que Mauricio Beuchot parece rehusarse a explorar en la raigambre inconsciente del símbolo, y por consiguiente, aún menos referirlo a una noción de inconsciente colectivo o de imaginario simbólico, de lo que tampoco expone abiertamente su rechazo. Aunque no hemos localizado alguna opinión al respecto, pensamos que en gran medida esta actitud pudiera deberse al fuerte interés de Beuchot por la verificación, y aunque admite una verificación contextuada, ${ }^{34}$ difícilmente ésta se podría aplicar al inconsciente y menos aún al imaginario simbólico, dado que en general estas nociones funcionan como "hipótesis metodológicas”. Por último, quizá también sea porque, valga la redundancia, el inconsciente es inconsciente.

Ésta es una de las más profundas diferencias entre las hermenéuticas aquí convocadas. Una vez más, la claridad en las distinciones conceptuales es una característica brillante y radiante de la Hermenéutica Analógico-Icónica, mientras que las distinciones de Ortiz-Osés son dibujadas sobre un fondo enigmático, condición que de forma intencionada él busca preservar, porque teme que las ideas muy claras lleguen a distanciar.

\section{e) Balance}

Hemos visto que ambas hermenéuticas resaltan su interés en el símbolo y sus posibilidades de interpretación, al ligarlo con la ontología. Pero cuando una filosofía afirma una característica del símbolo, la otra parece negarla, vemos puntos de fuerte confrontación que

32 Ibidem, p. 172.

33 Mauricio Beuchot. Hermenéutica, analogía y símbolo. México: Ed. Herder, 2004, p. 153.

34 Raúl Alcalá, op. cit., p. 18. 
se pueden atenuar si los correlacionamos con el resto de su pensamiento.

En cuanto al punto de este apartado vemos que si bien la Hermenéutica Simbólica dice rechazar razón en el símbolo, en el fondo no se refiere a lo mismo que la Hermenéutica Analógico-Icónica está afirmando. La primera usa los términos razón y racional y su rechazo tiene que ver más con ese concepto ilustrado, univocista, aunque aparte habla de una racionalidad relacional; y esta última filosofía habla más bien de racionalidad analógica. Analógica o relacional son nociones de racionalidad coincidentes, por lo que sus puntos diferenciadores más serios han de ir por otras áreas, y los giros en el desarrollo de sus interpretaciones hacen las sutilezas que las diferencian o que las separan hacia diferentes destinos.

El interés de la Hermenéutica Analógico-Icónica por el símbolo es más instrumental, con miras a la construcción de una ontología y de ahí a una antropología y hasta ética. En cambio, la Hermenéutica Simbólica tiene en su propio punto de partida ya una visión ontológica que expresa en el llamado principio de implicacionismo ontohermenéutico. Aquí el símbolo es la representación de sus presupuestos ontológicos, por lo que en ella la propia filosofía es método. Además, la raíz inconsciente del símbolo entra a protagonizar ese juego caótico de opuestos en la Hermenéutica Simbólica, mientras que esa raíz parece no servir tanto para los propósitos de la Hermenéutica Analógico-Icónica, aunque la supone.

\section{Bibliografía}

\section{Fuentes primarias}

Beuchot, Mauricio. Hermenéutica, lenguaje e inconsciente. México:

Universidad Autónoma de Puebla, 1989.

- Las caras del símbolo: el ícono y el idolo. Madrid: Ed. Caparrós, 1999.

Cultura, 2003.

2004.

Hermenéutica, analogía, icono y símbolo. 2005. 
UNAM, 2007.

Ortiz-Osés, Andrés. La nueva filosofía hermenéutica. Hacia una razón axiológica posmoderna. Barcelona: Editorial Anthropos, 1986. bao: Universidad de Deusto, 1989. 1995.

Metafísica del sentido. Una filosofía de la implicación. Bil- Visiones del mundo. Bilbao: Universidad de Deusto,

Amor y Sentido. Barcelona: Editorial Anthropos, 2003.

Fuentes secundarias

Alcalá Campos, Raúl. Hermenéutica, Analogía y Significado. Discusiones con Mauricio Beuchot. México: FES Acatlán UNAM, 2004.

Cassirer, Ernst. Antropología filosófica. México: FCE, 2006.

Gadamer, Hans Georg. Mito y razón. Barcelona: Paidós, 1997.

Heráclito. Fragmentos. Buenos Aires: Aguilar, 1973.

Nicol, Eduardo. Metafísica de la expresión. México: FCE, 1957.

Ricoeur, Paul. El conflicto de las interpretaciones. Ensayos de hermenéutica. Argentina: FCE, 2003.

Solares, Blanca y María del Carmen Valverde Valdés (ed.). Sym-bolon. Ensayos sobre cultura, religión y arte. México: Instituto de Investigaciones Filológicas, Centro Regional de Investigaciones Multidisciplinarias, UNAM, 2005.

Wellmer, Albrecht. Sobre la dialéctica de modernidad y postmodernidad. La crítica de la razón después de Adorno. Barcelona: Editorial Visor, 1993. 